\title{
Quality of Higher Education in Bangladesh: Governance Framework and Quality Issues
}

\author{
Golam Rabbani ${ }^{\mathrm{a}}$, Solaiman Chowdhury ${ }^{\mathrm{b}}$ \\ a Department of Public Administration, Faculty of Social Sciences, University of Rajshahi, Rajshahi, Bangladesh \\ b Department of Management Studies, Faculty of Business Studies, University of Rajshahi, Rajshah, Bangladesh
}

\begin{abstract}
This study is an effort to find out the policy options of higher education as well as students' perception on specific quality issues of higher education in Bangladesh. This paper is analytical in nature. To attain the objective of the study, 100 master level (MS) students, of Social Science Faculty, Rajshahi University have been interviewed. Respondents were interviewed using semi-structured pre-formulated questionnaire. Secondary sources, moreover, were reviewed to gather input to make this study reliable and valid. The study revealed that the greatest challenge to achieve the standard level quality in higher education is governance related problem. In this research the term governance covers management, policies and practices. There are some rules, regulations and institutional arrangement. Nevertheless, effective implementation of these policies is very rare due to lack of effective governance and professionalism. Furthermore, recruitment and promotion related decisions are not settled on the basis of qualification. In these cases, personal connection, party politics and inter-personal politics play significant role as determinants. Though there are some research works on quality of higher education in Bangladesh, yet it is very difficult to find out which shaded light on the student's perception about the quality issue of their education considering them as stakeholder or clients. In this backdrop, this study is an effort to find out the students' perception on specific issues of quality of higher education and offers the assessment of policy options which are supposed to use for ensuring the quality of higher education in Bangladesh.
\end{abstract}

Key Words: Quality, higher education, governance framework, Rajshahi University, Bangladesh

(C) 2014Beykent University 


\section{Introduction}

In industry, quality of product is critical, because quality of the products determines the survival of business. Similarly, universities are responsible to society for their products, such as the graduates, since government and parents provide money to universities to educate students by providing them quality education (Boyer 1990). Due to the wave of globalization and economic change, quality in higher education has gained paramount interest in the discussion of education policy across the globe. Many countries have emphasized to achieve international standards in their education system. With this aim, "national quality assurance mechanisms" have been introduced by various countries, and others are in the process of developing a suitable strategy (Stella, 2002: 13). In case of quality of higher education, South Asian countries are lagging behind. The Times Higher Education, one of the most credible source of world university ranking disclosed its university index, 2009 , and noted that out of one hundred top universities in the world five are from Japan, five from China (including three from Hong Kong), two from South Korea, two from Singapore and one from Taiwan ( Times Higher Education, 2010 ). No one university of South Asia achieved any position within hundred. On the basis of the assessment it can be said that situation of higher education in South Asia, including Bangladesh is very despondent. Bosworth and Collins (2003) investigated the education-quality of 84 countries across the globe considering a scale between 72 to minus 12. In the study, India and Sri Lanka scored 20.8, Bangladesh earned only 2.8 and Pakistan scored 11.3 (Cited in, Paul 2009). This data indicates universities or institutes of Bangladesh are not producing good human resources for its society. Researches and observations described that in every academic examination many students are receiving higher grades in undergraduate and graduate levels. Despite their excellent academic records, their communication skill is very poor, they have poor command on their academic fields of study, they have very little knowledge about the world's current affairs, and other disciplines. Furthermore, analytic skills and ability to deal with real life ambiguous situations and academic problems are woefully inadequate (Rahman, 2010; Khan 2010).

This is why, policy makers, academicians and practitioners have raised different issues of quality of higher education in Bangladesh. Various studies, for examples Aminuzzaman (2007), Masum (2008), and Kitamura (2006) stated that the quality of higher education in Bangladesh has been declining gradually over the last two decades. On the basis of above mentioned evidences, it is not an exaggeration to say that things have not followed right track in higher education sector over the decades though the demand for higher education have grown since independence of Bangladesh in 1971.

To revisit the situation and to provide policy suggestions, a number of research works, most of these are based on secondary information, were conducted on the quality of higher education in Bangladesh. Masum (2008) evaluated selected issues like: access, equity and efficiency and politicization of higher education in universities of Bangladesh, and provided policy recommendations. Monem (2007) dealt with the basic information of higher education in Bangladesh that covered issue of financing, position of quality assurance 
in different higher education policies and major problems in quality assurance of public universities. Andaleeb (2003) assessed students' satisfaction in the context of public universities using nine-factor model. Huda, Mujaffar, Akhtar and Ahmed (2010) measured students' satisfaction level in case of academic issues, support services and general issues in the private universities in Bangladesh. Moreover, Khan, Mridha and Barua (2009), Tasnima (2008) and Naser (2008) focused on the students' perception on the quality of private universities of Bangladesh. Though there are some research works on quality of higher education in Bangladesh yet it is very difficult to find out which captured on the student's perception on the quality issue of their education considering them as stakeholder or clients. In this connection, this study is an effort to find out the students' perception on specific issues of quality of higher education and it offers the investigations of policy options of higher education in Bangladesh.

After using a product or service of any industry/organization, consumers express their felling and attitude towards this service or product. This is the basis of consumer satisfaction (Metawa and Almossawi, 1998). In case of services, Naser, Jamal and Al-Khatib (1999) described that service quality and customer satisfaction are linked to service quality and its features. However, according to the concept of "client satisfaction" (Philip, G. Altbech 1998), students can be considered as consumers of the service of education, and they have the right to obtain the best quality education. Literature review reveals that recent research do not capture the student perception on quality of higher education of public universities of the country. In this perspective, the study was intended to focus the quality issues of higher education in Bangladesh by assessing policy framework and capturing students' perception. To know students' perception on quality of higher education of public universities of Bangladesh, Rajshahi University has been taken as a case of investigation. Rajshahi University is the second largest university in Bangladesh, established in 1953. Since its inception, people expected that a university that is situated outside the capital will gain its academic ${ }^{a}$. There is a gap between the expectation and reality. A research (Alam and Rahman, 1993) unveiled that among 131 finally recruited candidates of administration cadre ${ }^{\mathrm{b}} 100$ was from Dhaka University, 20 was from Rajshahi University and 10 from other universities. Furthermore, recent research (Panday and Jamil, 2009) found that the university has typically followed a process of recruit and promotion of teachers wherein political consideration get more priority than merit, and that influences the degradation of quality of education and overall status of the university.

\section{Quality Dimensions, Indicators and Quality Measurement Process: A Theoretical Note}

One of the major goals of education is to impart knowledge, values, attitudes and skills which are needed to empower people to bring the changes in their life. This goal can only be achieved through providing quality education. Exception (high standards), consistency (zero defects), meeting the stated purposes,

\footnotetext{
a This writing only reviewed the information of public service because university based employment related information is very hard to get

${ }^{\mathrm{b}}$ One of the prestigious positions in the civil service of Bangladesh, and this cadre is known as an elite cadre.
} 
value for money and qualitative changes among the participants (the value-added factor) -are the five different approaches which can be used to explain the meaning of word "quality" (Delors, 1996). It is expected that when education will be quality driven then it will be helpful throughout life. So a report described, "Education throughout life is based on four pillars: learning to know, learning to do, learning to live together and learning to be"(Delors, 1996: 37). In other words quality education will prepare a student to face the challenges of real life situation and global changes. Of course, higher education considers the social, economic, and environmental contexts of the country. Ignoring the policy context, education system per se cannot ensure quality of education. This is why the issue of policy and assurance of quality comes forward.

Different documents of quality assurance show internal and external mechanisms of quality assurance. When any educational institution ensures quality of its product within its own intra-organizational mechanism, this is called internal quality assurance. On the other hand, when national level institutional policies and practices are used in quality assurance - this is called external process of higher education. In case of higher education, every university always has got policies and practices, which are designed to assure the quality of education. Of course, all universities follow a national policy framework designed by the state to assure academic standards (Dill, 2007). What is quality of higher education? According to UNESCO (2008: 89): "Assurance of quality in higher education is a process of establishing stakeholder confidence that provision (input, process and outcomes) fulfils expectations or measures up to threshold minimum requirements."

Another researcher (Materu, 2007: 3) mentioned,

"Quality assurance is a planned and systematic review process of an institution or program to determine whether or not acceptable standards of education, scholarship, and infrastructure are being met, maintained and enhanced. A tertiary institution is only as good as the quality of its teaching staff - they are the heart of the institution who produce its graduates, its research products, and its service to the institution, community, and nation".

Quality of education is a dependent variable which is affected by some factors like- vision and goals, the talent and expertise of the teaching staff, admission and assessment standards, the teaching and learning environment, the employability of its graduates (relevance to the labor market), the quality of the library and laboratories, management effectiveness, governance and leadership (Materu, 2007).Bonaccorsi and Daraio (2007) identified six broad variables, like- general information on higher education institutes, revenues, expenditures, personnel, education production, and research and technology production to measure the quality of higher education. Davies (1996) described that clear stable framework (Policies, rules and guidelines), personal competence of staffs (skill, knowledge and attitude) and support (encouragement, motivation, reward and peer support) are the dominant factors to ensure the quality in higher education. 
To assess the viability of these indicators in the context of Bangladesh, different researches and observations were reviewed. "International Workshop on the Development of Measurements for Higher Education Quality Assurance in Bangladesh (2007)" proposed a set of indicators to measure the quality of higher education in Bangladesh which includes- purpose and objective, faculty, instruction, student service, library, laboratories, infrastructure and research culture as most important indicators (Villanueva 2007). Investigating the quality of higher education in Bangladesh Andaleeb (2003) mentioned that seven issues are crucial for ensuring quality of higher education in Bangladesh. These are namely, teaching quality, method, content, peer quality, direct facilities, indirect facilities and political climate.

On the basis of above mentioned theoretical discussion it can be said that different input factors, design factors and output factors can be used to measure the quality of higher education in Bangladesh. In this connection, policy framework (formal polices and guidelines), quality of teaching staffs (skill, knowledge and attitude) and support factors (libraries and internet facilities for students) have been considered to assess the quality of higher education in Bangladesh.

This paper is analytical in nature. In this research , 100 master level (MS) students, of Social Science Faculty, Rajshahi University (10 respondents from each department with similar portion of male and female), took part in this research. Instead, an open invitation was issued to participate in the research. Respondents were interviewed using semi-structured pre-formulated questionnaire. Researchers collected primary data in May 2010. Secondary sources like, recent publications, journals, books, research reports, and newspapers have been reviewed to gather input to make this study reliable and valid.

\section{Higher Education in Bangladesh}

The education system of Bangladesh may be broadly divided into four levels viz., primary education, secondary education, higher secondary education and higher education. Higher Education is provided basically by the universities or higher education institutes. However, more than 4000 colleges also provide graduate and undergraduate programs under the National University of Bangladesh. The pre-requisite qualification to enter into the university level education is obtaining Higher Secondary School Certificate (HSC) (12 years education).

\section{Contextual Factors}

\subsection{Governance Framework and Institutional Arrangement}

University of Rajshahi is one of the largest Universities of the country having highest seat of learning in the northern region of Bangladesh. Rajshahi University was established on July 6, 1953 and has been providing higher education and research over 57 years. The university is located at the green premises of Motihar which is very close to the river Padma and seven $\mathrm{km}$. east from the Rajshahi City Center. Altogether there are 08 faculties, 5 Institutes and 47 departments in the University of Rajshahi. To ensure the quality in higher education the university follows national policies approved by the government/university grants 
commission and also, has its own policies and governing mechanism as an autonomous body ( for more detail, http://www.ru.ac.bd/).

National policies or statements issued by quality assurance agencies or other organizations help bring quality in higher education. These policies give framework to the university authorities for creating a culture of quality in their institutions (OECD, 2010). In this regard, we delved into the policy framework and institutional arrangement in ensuring quality of higher education in Bangladesh.

The University Grants Commission (UGC) of Bangladesh was established under the President's Order (P.O.) No. 10 of 1973 which is the apex statutory body in Bangladesh to supervise, maintain, promote and coordinate university education. Major responsibilities of UGC are maintaining standard and quality of all the public and private universities in Bangladesh. The UGC is also assigned to assess the needs of the public universities in terms of funding and to provide advises to Government in various issues related to higher education in Bangladesh (UGC, 2008). It is alleged that the University Grants Commission (UGC) is not as successful as it was expected to regulate the public universities. However, no noteworthy initiative has been taken by UGC to introduce a self-regulatory accreditation system for public or private universities (CPD, 2001; Chauhan, 2010).

In Bangladesh, public universities are established under separate Act of the Parliament. According this Act the respective university enjoys enormous power about opening new subjects, creating posts of faculties, human resource management, including reward and punishment, preparing syllabus and curricula etc. As other public universities, Rajshahi University is governed according to The Rajshahi University Act, 1973 (Act No. XXVI of 1973, Government of Bangladesh). According to Section 19 of this Act-the Senate, the Syndicate, the Academic Council, the Faculties, the Departments, the Committees of Courses, the Boards of Advanced Studies and the Selection Boards are the authorities that are responsible for ensuring the quality of teachers and graduates.

Every department forms "academic committee" and "committee of courses". "Academic Committee" is formed by every teacher of the department, which is authorized to supervise, monitor and guide the department for keeping its activities on track for achieving its ultimate objective. All the teachers of the department are member of "committee of courses", and external members (one or two) are invited by the department from outside the university who have reputation for his/her expertise in this field. Usually, the department organizes the meetings of committee of courses once a year to redesign or revise the curriculum. After evaluating the curriculum the department submits it to the Faculty ${ }^{\mathrm{c}}$ meeting. After getting approval from Faculty meeting it goes to "academic council", of the university. Finally, it goes to

\footnotetext{
${ }^{c}$ Faculty office is a coordinating hub of some departments, and all Professors of all departments of a specific are member of this committee

${ }^{d}$ Academic council is the apex body for ensuing quality of education consisting of all professors of the university
} 
syndicate for final approval. Senate is authorized to amend and ratify the approved proposals of the Syndicate. It considers and provides approvals of annual report, annual accounts and financial estimates presented by the Syndicate ${ }^{\mathrm{e}}$ (Rajshahi University Act, 1973 and Rajshahi University Calendar ${ }^{\mathrm{f}}, 2006$ ).

According to laws and regulations, Rajshahi University has a wide-ranging institutional framework to oversee the academic activities, but compliance of these rules and regulation in detail manner is rare. In most of the cases, authorities organize meetings only for maintaining formalities. Academic staffs are not interested in academic issues because they are involved with different types of other activities like, consultancy, personal business, class taking in private universities and politics (Varghese, 2004). In some cases, syndicate and decision making bodies overlook malpractices and noncompliance to the rules and regulations. In spite of having a legal-institutional framework for ensuring quality and preventing the malpractices, in reality, there has been little organized effort. Interpersonal communication, intra-party and inter-party ties, kith and kin network, regional identity/regionalism (coming from same geographical area) and previous teacher-student relationship hamper the quality control mechanism in Rajshahi University. Basically, Bangladeshi society is hierarchical, and due to dominance of collectivism, people try to maximize the benefit of friend networks, relative networks and political network for taking undue benefits which foster the nepotism and favoritism (Siddique 2006; Aminuzzaman, 1993; and Jamil 2007). Recently, syndicate of Rajshahi University is taking some positive initiatives, for instance, it has recommended for probing corrupt practices during 2001-2008 in the university (The Financial Express, 22 July 2010).

\subsection{Quality of Teaching Staffs}

Teaching is a specialized profession which requires special knowledge and training. Some time it is called as technology to teach other (Reynolds, 1998, Cited in Times Higher Education, 2010). Atwood (2007) described that 'core' aspects of quality education are learning-teaching and course organization. Researchers like McAffrey et.al. (2003), Rivkin et.al. (2005) and Rockoff (2004) revealed that teachers' classrooms behaviour or management of educational activities in the institution play important role to give quality education to university students. To investigate the teachers' quality, students were asked about "lesson clarity" (Do the teachers make the lesson clear?), instructional variety (Do teachers use varies instruction style?) and "teacher's effective time management" (Do teachers conduct class regularly?). Among the respondents, $80 \%$ replied positively when asked them whether the teachers make the lesson clear and $15 \%$ replied negatively and 5\% made no comment on it. Most of the students added that junior teachers quality are not up to the mark and senior teachers are very busy and not updated about tools, techniques and evidence. According to 70 percent respondents, most of the teachers both from senior and

\footnotetext{
${ }^{\mathrm{e}}$ Apex internal decision making body of public university

${ }^{\mathrm{f}}$ By law of Rajshahi University
} 
junior level are very stereotype to deliver their lecture in the class room, 20 percent respondents viewed that few teachers follow interactive techniques in class room and rest of the respondents made no comment on it. Among the selected respondents 56 percent have expressed their positive responses about the class conducted by their teachers regularly and 44 percent given the negative responses in this regard.

It is hard to find out a research about 'lesson clarity' and 'instructional variety' in the higher education of Bangladesh. Monem (2007) described that the present method of teaching in basic subjects are ineffective because of outmoded method and lack of philosophical under. In addition, students' dissatisfaction and their comment about quality of teachers indirectly showed that there are gaps in lecture delivery and making the class interactive using different instructional style. In public universities, an irregularity in class taking is a common phenomenon. In many cases chairmen of departments and directors of institutes failed to convince the senior and mid level colleagues to conduct class regularly. Without taking regular class, senior teachers complete the class by a few lectures or she/he handovers the class relatively to junior teacher of the same department or same institute (Rahman and Islam 2011; Paul 2009). Teachers do not give enough time in the class and academic work, due to their other involvements (consultancy, teaching in private universities etc). Many other electoral/ representative functions like electing Vice Chancellors Deans, Syndicate and Senate members permissible under the University Act, create a political culture rather than congenial academic culture. The political culture, also, acts as a hindrance to ensure accountability of the teachers.

Teacher recruitment is a vital factor in ensuring quality of higher education. A group of researcher (Darling Hammond, Berry, Haselkorn and Fideler, 1999) stated that, "The issue of teacher quality is inextricably linked to recruitment, for in recruiting teachers [institutions] wish to attract individuals who are well prepared, effective and who will remain in the teaching profession long enough to make a difference (Cited in, OECD, 2010 : p 42)".

In Bangladesh, university authority irrespective of political regime over the decades preferred recruiting 'voters', not 'teachers' that adversely affected the quality of university education ( Khan, 2010 Bayes 2009;CPD, 2001). Panday (2009a) investigated the recruitment of teachers in Rajshahi University, found that "one candidate having four first classes did not get selection even though five candidates having three first classes managed to get selection". In teacher's recruitment political loyalty or family relationship or any other group identity get priority over the merit (Mannan 2010; Monem 2007).

\section{Support factors}

In the higher education not only teachers' quality but also support factors, e.g. syllabus, research opportunities, library and internet facilities, motivational and reward factors for teaching staff have a great influence in ensuring quality higher education.

\subsection{Syllabus}


In higher education, the knowledge content which are presented in the lectures and teaching materials are important factor. In this view, the best education institute is one who transmits the best possible body of knowledge in the best possible ways ( Mohanan,nd ). Syllabus or curricular is a component of higher education which reflects the nature of body of knowledge. The curriculum of higher education should be regularly restructured in accordance with modern knowledge and research to make it as standard as acceptable in international level. From this perspective, we captured the students' perception on syllabus (Is your curricula or syllabus okay? Yes or no? Why). Most of the respondents (62 percent) viewed that the content of their syllabus is not adequate to meet the present and upcoming challenges of changing world. Among the respondents, 38 percent think it is okay. They pointed out that study of curricular need to be modified according to the demand of job market and changing pattern of knowledge in the global context. Curricular reforms in Bangladesh are very common from the past but no radical reform was so far done. The system of higher education in Bangladesh possesses some blockages so far as curricular reform is concerned. The composition of university bodies, the organizational set up of departments in universities, lack of connection with internationally recognized higher education institutes and very limited connection of academic staffs with updated knowledge and research are recognized as major problems in curricula reform in Bangladesh (Islam, 2007 ; Monem 2007).

\subsection{Research Opportunities}

Main responsibility of higher education institution is knowledge creation and dissemination. In university level education, preparation of manuals, monographs, articles, reports, editing etc., are well known as research activates (OECD, 2010). Combinations of theoretical and practical knowledge are integral parts to create professionals with conceptual clarity, analytical ability and specialized knowledge in their respective field. In this connection, the research quality and teaching quality ratings are valid indicators in measuring quality of higher education (Patrick and Stanley 1998). From this view point, we have investigated the nature of research culture in RU. In this university there are different options in doing research in undergraduate and graduate level. Research based Master, Master of Philosophy (M.Phil ) and Doctorate of Philosophy $(\mathrm{PhD})$ degrees are offered by $\mathrm{RU}$. We asked master level students, do you think that your institute gives adequate emphasis on doing research? Against this question 89 percent students replied that our institution does not give emphasis on research based education. The reasons underlying neglect of research in higher education are lack of teachers' commitment to search for knowledge, inadequate teaching norms of academic behavior, lack of institutional policy and support for research (Rahman, 2009; Monem, 2007) deserve to be mentioned. Khan (2010) stated that many Associate Professors and Professors of public universities who do not have any research based degree (M. Phil and Ph.D. degrees) are supervising M. Phil and $\mathrm{PhD}$ students. Above statement makes it clear the prevailing scenario of research based education in Bangladesh. Also, promotion policy of academic staffs does not give emphasis on research and publications. Under promotion restructuring rules, academically weak candidates without having a MS and 
$\mathrm{PhD}$ with minimum number of publications in local journals (non-referred journals) receive promotion to next higher position on the basis of length of service in the public universities (Islam 2010).

\subsection{Libraries and Internet facilities for Students}

From the time of earliest civilization libraries have been considered to be the storehouse of thoughts and knowledge. Basically libraries collect documents and organize records of human thoughts and knowledge for creating and disseminating new knowledge. The link between education and library is well connected and logically deep rooted because both educational institutions and libraries work with knowledge (Šušol, 2009). Since 1955, Rajshahi University Central Library has been providing library facilities for students, teachers and researchers. Total number of reading materials including books, journals, documents and reprints are about 3,00,000. Access to a huge number of online journals is open for teachers and students of RU via the Programme for the Enhancement of Research Information (PERI). Users can use these journals and resources through the university network without any password (Roknuzzaman, 2006). The university has air-conditioned library, enough reading space and readers-friendly environment. Also, every department and institution has their own seminar library.

It this perspective, this research investigated students perception on library use (Do you use library regularly? Yes or not and why?). Maximum students (70\%) viewed that they do not go to library regularly, because updated books and other journals are not available, official procedures of drawing books and managing to get photo copy are very rigid. Most of the students are partially dependent on class notes of senior students who did well in academic examinations of previous years. Most of the students do not know about PERI.

Internet is now well known as a popular source of information. In this research we asked the students, 'did you get internet facilities from University? In response, 90 percent students said that they did not get internet facilities from universities. Among the respondents 45 percent added that they try to use internet at their own expense. Most of the departments (except some ICT, physics and computer science departments) do not have computer lab with internet connection. Central library and counter centers have about 50 computers for only research students (Masters, M.Phil, and PhD). A previous research found that only 40 percent research students used computer and internet for practical and research purposes, and general students had limited access to internets (Roknuzzaman, 2006).

\section{Conclusion}

Quality of higher education in Bangladesh is not at the level to match international standard which is considered to be essential to cope with the upcoming challenges that world is confronted with. Many researchers found that quality of higher education is deteriorating day by day. Why is this situation? Above mentioned discussion revealed that the greatest challenge to achieve the desired output is governance related problems which includes authority, policies and practices. 
To improve the quality of higher education in Bangladesh, there are some rules, regulations and institutional arrangement. However, implementation of these policies is very rare due to governance failor. Furthermore, recruitment and promotion related decisions are not prioritized on the basis of qualifications. In these cases, personal connection, party politics and inter-personal relations got preference than merit.

To some extent, public universities have lack of enthusiasm to introduce time oriented course curriculum, because academicians have low connection with the practical fields and international community. Furthermore, academicians did not get such type of congenial environment to teach time demanding courses or subjects. Public university, especially Rajshahi University recently has taken some initiatives to access the world class electronic referred journals. But very few researchers and academics use these facilities.

It can be concluded that to ensure the quality of higher education, an integrated approach has to be taken. For this reason, at first existing policy framework and institutional arrangement should be implemented and, re-examined. It is very important to say that this framework will be quality driven. The objectives of higher education cannot be achieved having ignored the basic norms and spirit that universities by and large strive to attain throughout the world. 


\section{References}

Aminuzzaman, S. (2007), "Overview of Quality Assurance in the context of Bangladesh". Paper presented in a workshop organised by American International University Bangladesh, Dhaka, Bangladesh. Aminuzzaman, S M. (1993), "Management Culture of Public. Bureaucracy in Bangladesh", Social Science Review, Vol. X (1): 83-106

Andaleeb, S. S (2003), Revitalizing Higher Education in Bangladesh: Insights from Alumni and Policy Prescriptions, Higher Education Policy, 16 :487-504

Bayes, A (2009), "Beneath the Surface: Digital Bangladesh", The Daily Star, 2009-01-11

Bonaccorsi, A and Daraio, C. (2007), "Universities and Strategic Knowledge Creation; Specialization and Performance in Europe”. Massachusetts: Edward Elgar Publishing Ltd.

Boyer, E.L. (1990), "Scholarship Reconsidered: Priorities of the Professoriate". Princeton : N.J. Carnegie Foundation.

Chauhan, C. P. S. (2008), "Higher Education: Current Status and Future Possibilities in Afghanistan, Bangladesh, Bhutan, India, Maldives, Nepal, Pakistan, and Sri Lanka; Analytical Reports in International Education, 2 (1), 29-48

Huda, S.S.M , Mujaffar, A. T , Akhtar, A, Ahmed J. U ( 2010) "The State of Private Universities in Bangladesh: An Evaluation of Students Perception", Information Management and Business Review,1(1),16-27

Husain, S. A (2000), “Campus politics: Whys and why nots”, The Daily Star, 26 March, 2010

Islam, F (2007), "Some issues of higher education in Bangladesh: Analysis of demand, problems and trends", The Financial Express, 27 June

Jamil, I (2007), “Administrative Culture in Bangladesh”, Dhaka: A H Development Publication in Bangladesh.

Khan, M. M ( 2010), "State of Public Universities in Bangladesh", The Daily Star The Independence Day Special Issue, 26 March

Kitamura Y.(2006). "Expansion and Quality in Bangladesh," International Higher Education, No.44.

Monem, M (2007), "Higher Education in Bangladesh: Status, Issues and Prospects" in Gamage Sujata (2007) ed. Higher Education in Bangladesh, Malaysia, Philippines and Sri Lanka; Srilanka Education Forum

Mannan, A (2010). "Higher Education Deficits in Draft", The Daily Star, 25 February, 2010

Masum, M. (2008) "Higher Education in Bangladesh: Problems and Policies", Journal of the World Universities Forum, Volume 1, (5).

Materu P (2007), "Higher Education Quality Assurance in Sub-Saharan Africa Status, Challenges, Opportunities, and Promising Practices", World Bank Working Paper No . 124, Africa Region Human Development Department 
McCaffrey, D.F.,Lockwood, J. R., Koretz, D., Louis, T.A. \& Hamilton, L. (2004) "Modes of value added modeling of teacher effects”. Journal of Educational and Behavioral Statistics, 29:1, 67-101.

Mohanan K., P (nd), “Assessing Quality of Teaching in Higher Education", http://www.cdtl.nus.edu.sg/publications/assess/unpack.htm, accessed on, 25.02.2011

Monjur M., M (2002), "Quality Assurance in Public Universities of Bangladesh-An Overview” A paper presented in a seminar on "Quality Assurance in Higher Education in Bangladesh" organized by UGC and held in Dhaka in July 2002

OECD (2010), Learning Our Lesson: Review of Quality Teaching In Higher Education

Panday, P. K and Ishtiaq J. 2009. "Impact of Politicization on the Recruitment of University Teachers in Bangladesh: The Case of the University of Rajshahi." Paper presented at the NAPSIPAG International Conference on "Human Capital and Good Governance: Transition towards Knowledge Based Development and Well Being." Kedah, Malaysia: Universiti Utara Malaysia, 11-13 December.

Panday, P. K (2009a), "Revitalising Rajshahi University”, the Daily Star, 01/07/2009.

Patrick, W. J. and Stanley E. C (1998), "Teaching and Research Quality Indicators and the Shaping of Higher Education", Research in Higher Education, Vol. 39, No. 1, 1998

Paul, B. P. (2009), Reforming higher education for growth, The Daily Star, November 15, 2009

Rahman, M. O. (2010), "Private and public universities: Are they delivering?" The Daily Star, The Independence Day Special Issue, 26 March

Rahman, M. M, and Islam, S. (2011), "Higher Education Vying for quantity or quality?" The Daily Star, January 8

Rahman Nader ( 2009). Education: Lets Get Digital, The Daily Star, 10 September

Rivkin, S.G.,Hanushek, E. A. and Kain, J.F. (2005), Teachers, schools and academic achievement. Econometrica, Econometric Society, 73 (2) : 417-458.

Rockoff, J.E. (2004), The impact of Individual Teachers on Student Achievement: evidence from panel data. American Economic Review, 94 (2): 247-252.

Roknuzzaman, M. (2006), A survey of Internet access in a large public university in Bangladesh, International Journal of Education and Development using Information and Communication Technology (IJEDICT), 2(3): 86-105.

Siddique K,( 2006). Towards Good Governance in Bangladesh: Fifty Unpleasant Essays, University Press Limited, Dhaka

Stella A, (2004), 'External Quality Assurance in Indian Higher Education: developments of a decade', Quality in Higher Education, 10(2) :115-127

Summer (2006), The Boston College Center for International Higher Education, 23-24.

Šušol, J. (2009), Higher Education and the Academic Library: Perspectives for Slovakia, Educause Review, 44 (4): $66-67$ 
Times Higher Education (2010). Times Higher Education-QS World University Rankings 2009, http://www.timeshighereducation.co.uk/hybrid.asp?typeCode $=438$

UNESCO (2008), "Reinventing Higher Education: Toward Participatory and Sustainable Development". Bangkok: UNESCO Bangkok.

Villanueva C., C. (2007). "Proposed Indicators/Measures of Higher Education Quality Assurance in

Bangladesh", Working Paper 2, International Workshop on the Development of Measurements for Higher Education Quality Assurance in Bangladesh, Pan Pacific Sonargaon Hotel, Dhaka, Bangladesh, 30-31 May 